\title{
Analysis of the airflow at the centre of the upper plateau on the Iberian Peninsula and its link to $\mathrm{CO}_{2}$ and $\mathrm{CH}_{4}$ concentrations
}

\author{
Isidro A. Pérez, *ib M. Luisa Sánchez, M. Ángeles García, Nuria Pardo and \\ Beatriz Fernández-Duque \\ Department of Applied Physics, Faculty of Sciences, University of Valladolid, Spain
}

\begin{abstract}
Air trajectories are useful tools to investigate the airflow and transport of substances released into the atmosphere. Web-based models are widely used to calculate trajectories reaching places that are being studied. This article considers 6 years of air trajectories as of October 2010 together with $\mathrm{CO}_{2}$ and $\mathrm{CH}_{4}$ concentrations. A bivariate smoothing function that employs the radial distance and direction of the trajectory to the measuring site was used to form trajectory groups from the minima of this function. Varied radial and angular windows were assayed to investigate the behaviour of the smoothing function. Curves associated with the number of minima were L-shaped and the windows selected corresponded to the 'knee' of the curves. Seven trajectory groups were considered to observe the response of the procedure against the radial distance and the direction. Seasonal evolution revealed the greatest radial extent for winter and the lowest for summer. Moreover, trajectories from the Atlantic Ocean were the most frequent. $\mathrm{CO}_{2}$ and $\mathrm{CH}_{4}$ concentrations were detrended using a linear function, and average trends were 2.34 and $0.0085 \mathrm{ppm}_{\text {year }}{ }^{-1}$, respectively. Annual cycles of detrended concentrations were very soft and were linked to the site's ecosystem. $\mathrm{CO}_{2}$ presented one maximum in spring linked to substantial vegetation growth, and one minimum in summer, when vegetation dies and dispersion is maximum. $\mathrm{CH}_{4}$ maximum was observed in winter although the minimum was found in summer and attributed to oxidation with the hydroxyl radical in the troposphere and to dispersion in this season. Analysis of concentration trends for the groups proposed revealed the opposite behaviour of both gases in summer. Finally, maximum $\mathrm{CO}_{2}$ concentrations were marked by trajectories from North Africa affected by nearby cities, whereas minimum concentrations for both gases were noticeable for trajectories from the ocean in summer.
\end{abstract}

KEY WORDS METEX; air trajectory; carbon dioxide; methane; kernel density; GHG trend

Received 8 March 2017; Revised 12 September 2017; Accepted 26 September 2017

\section{Introduction}

Air trajectories are useful tools to investigate the atmospheric paths reaching sites which are the object of particular studies. Although their fields of application vary enormously (Pérez et al., 2015a), there are two main kinds of uses. One focuses on meteorological applications, such as moisture transport, and the other analyses the impact of pollutants released into the atmosphere by the sources. One key point favouring the calculation of air trajectories is the development of websites where requests may be submitted and trajectory results are returned.

Systematic calculation of air trajectories has one noticeable advantage, namely, a detailed knowledge of the airflow. However, its main drawback is the large number of variables involved, requiring procedures that can simplify their handling for which the cluster method is usually considered. Cape et al. (2000) used an agglomerative and hierarchical algorithm where each trajectory is a cluster

\footnotetext{
* Correspondence to: I. A. Pérez, Department of Applied Physics, Faculty of Sciences, University of Valladolid, Paseo de Belén, 7, 47011 Valladolid, Spain. E-mail: iaperez@fa1.uva.es
}

at the first step. Distances between pairs of clusters are calculated, and the closest two clusters are joined. A statistic is employed to halt the process.

When the number of trajectories is high, a non-hierarchical algorithm must be used to reduce calculation time. Dorling et al. (1992) proposed a previous seed to form the initial clusters. In the following step, pairs of clusters whose mean trajectories are the closest are merged. The process is halted with the aid of a statistic. However, the calculation time may be long, even in this case.

Various statistics were used to select the number of clusters. Morgan et al. (2009) employed the coefficient of determination and root-mean-square distance between clusters. Both statistics are commonly used although total spatial variance and silhouette are also sometimes considered (Kumar et al., 2011; Notaro et al., 2013). Consequently, although cluster analysis is widely employed, there is no single fixed method, because certain decisions must be taken when implementing the procedure, convergence for which may prove lengthy and time-consuming.

Alternative procedures have been investigated in order to obtain information from detailed trajectory data sets $(\mathrm{Li}$ 
et al., 2012). Trajectory sector analysis considers the time spent by each trajectory in different angular sectors, while the potential source contribution function method analyses the trajectories passing on each cell in a grid that covers the whole region being studied.

This article focuses on airflow research because it suggests a fast procedure to obtain trajectory groups which display similar distances and directions. At a second stage, the influence of airflow on $\mathrm{CO}_{2}$ and $\mathrm{CH}_{4}$ concentrations is also considered.

One noticeable feature of this study is the use of a smoothing function to determine the trajectory groups. Similar functions have been employed in nonparametric trajectory analysis (Henry, 2008; Henry et al., 2011), where the aim was to determine the concentration distribution.

One key point concerning the use of the smoothing function is determining its accompanying window. The expressions usually considered are based on the standard deviation of observations. However, one section of this study is devoted to analysing an alternative procedure for selecting this window.

$\mathrm{CO}_{2}$ and $\mathrm{CH}_{4}$ concentrations were recorded at a semi-natural site (Pérez et al., 2009). Because both gases show a slight increase over time, their trends must be investigated when the period analysed is long enough and concentrations need to be detrended. The final sections of the current analysis are devoted to investigating the evolution of these gases and to obtaining contrasts between their concentrations in the trajectory groups formed.

\section{Materials and methods}

\subsection{Experimental description}

The measurement site was the Low Atmosphere Research Centre (CIBA) $\left(41^{\circ} 48^{\prime} 50.26^{\prime \prime} \mathrm{N}, 4^{\circ} 55^{\prime} 58.53^{\prime \prime} \mathrm{W}, 852 \mathrm{~m}\right.$ a.s.1.), where Mediterranean scrubland is the main vegetation. The period covered in the present study extended over 6 years and commenced on 15 October 2010.

Air trajectories were provided by the METeorological data EXplorer (METEX) model (Zeng et al., 2010). Input data are the coordinates of the arrival site and height. The rest of the data are obtained by the model from the National Centres for Environmental Prediction's Climate Forecast System (Saha et al., 2014). In order to investigate the extent of the trajectory and avoid the influence of low orographic features, backwards trajectories were calculated every hour at $500 \mathrm{~m}$ a.g.l. at the measurement site and over a period of 4 days.

$\mathrm{CO}_{2}$ and $\mathrm{CH}_{4}$ dry concentrations were measured with a Picarro G1301 analyser at $1.8,3.7$ and $8.3 \mathrm{~m}$ every $10 \mathrm{~min}$ at each level. Calibrations, which were made with three National Oceanic and Atmospheric Administration (NOAA) standards each 2 weeks, were used to slightly correct measurements by means of linear equations.

Half-hour averages of concentrations were systematically calculated. However, because the lowest temporal resolution of the METEX model is $1 \mathrm{~h}$, hourly averages of semi-hourly concentrations were obtained. Availability of hourly observations was around $83 \%$. There were noticeable gaps in August-December 2014 and in August 2013, 2015 and 2016 for reasons beyond the control of the analyser, which functioned correctly during the period of measurement.

Various expressions have been used to explain $\mathrm{CO}_{2}$ evolution, with the exponential and fourth-order polynomial being among the most complex (Inoue et al., 2006; Artuso et al., 2009), and the linear among the simplest (Liu et al., 2015). In this analysis, hourly concentrations of both gases were detrended by fitting this last equation

$$
x=A+B t
$$

where $x$ is the concentration and $t$ the time from the beginning of the measurement campaign.

In order to link concentrations to sources and sinks, Normalized Difference Vegetation Index (NDVI) and population densities were obtained from the National Aeronautics and Space Administration (NASA) Earth Observations web with a $0.1^{\circ}$ resolution (NEO-NASA Earth Observations, 2017). NDVI monthly values were downloaded for the measurement period. However, density population was available for the year 2000 .

\subsection{Kernel density}

Each air trajectory is formed by 97 pairs of longitudes and latitudes $\left(\lambda_{i}, \phi_{i}\right)$, respectively. These pairs were first replaced by only one pair $\left(\lambda_{C}, \phi_{C}\right)$ which is the trajectory centroid formed by averages of trajectory latitudes and longitudes. Radial distance $r_{i}$ and direction $d_{i}$ from each centroid to the measurement site $\left(\lambda_{0}, \phi_{0}\right)$ were then calculated with the aid of basic spherical trigonometry relationships (Snyder, 1987).

Kernel density $\rho$ is usually obtained for two variables ( $a$, b) by a product of functions (Wilks, 2011), such as

$$
\rho(a, b)=C \sum_{i=1}^{n} K\left(\frac{a-a_{i}}{h_{1}}\right) K\left(\frac{b-b_{i}}{h_{2}}\right)
$$

where $K$ is the smoothing kernel, $h_{1}$ and $h_{2}$ are smoothing parameters or windows and the constant $C$ guarantees that the volume below the surface $\rho(a, b)$ is 1 . Because this requirement is not necessary in this study, $C$ was considered equal to 1 .

The Gaussian kernel is frequently considered although calculation time increases greatly when the number of observations grows, because all observations are involved. Another common kernel is the Epanechnikov kernel, whose main computational advantage is that the observations employed are limited by the corresponding window (Henry et al., 2002; Donnelly et al., 2011). In this article, the following quartic kernel (Fisher, 1993), which has scarcely been considered to date, but which displays the same advantage as the Epanechnikov kernel, was used.

$$
K(s)=\left(1-s^{2}\right)^{2},-1<s<1
$$

However, Figure 1(a) reveals that the product of two equal kernels does not exclude observations beyond a 
(a)

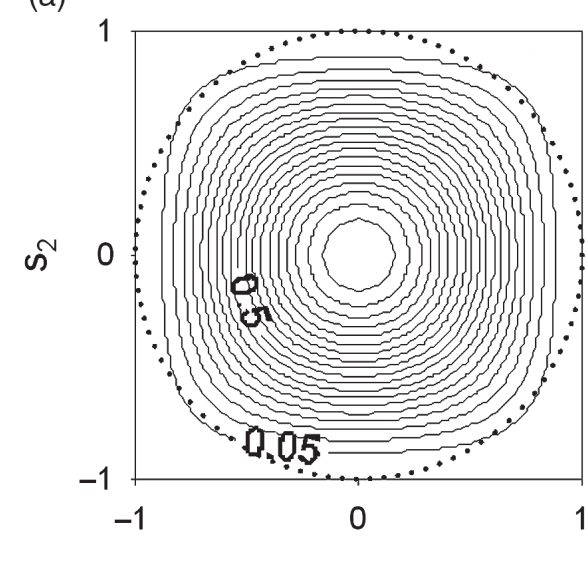

(c)

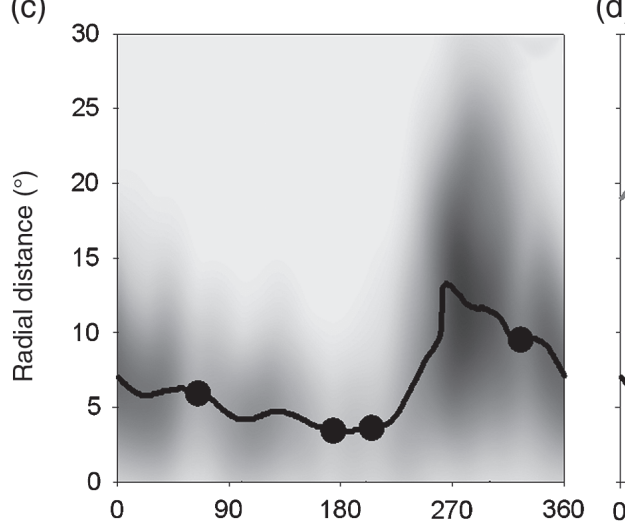

(b)

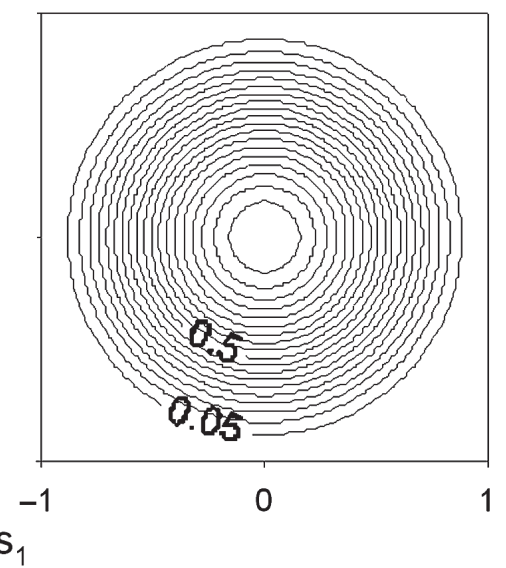

(d)

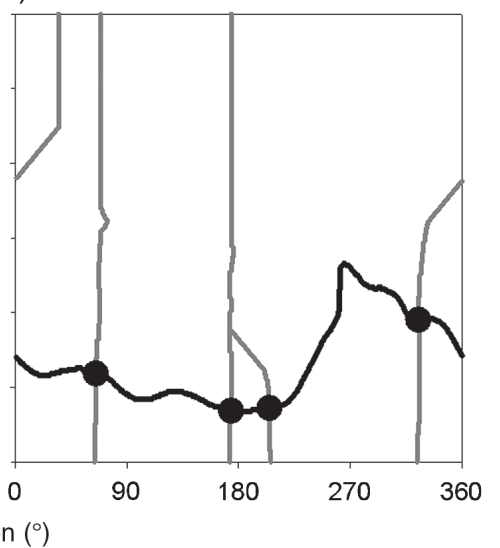

Figure 1. (a) Density contours corresponding to the product of two kernel functions given by Equation (3); dotted circumference corresponds to a distance equal to 1 from the origin. (b) Density contours for the kernel function given by Equation (3) with the distance from Equation (4). (c) Density given by Equation (7) in grey, where darker areas correspond to higher densities. The black line joins the points of maximum density for each direction. The black dots are minima of density in the black line. (d) The grey lines are drawn from the black points by searching for the lowest density in the radial distance.

distance equal to 1 from the origin, because observations between the square and the dotted circumference are considered although with a low density. This study follows an alternative method by considering only one kernel with a variable that accounts for the distance to the origin, such as

$$
s=\sqrt{s_{1}^{2}+s_{2}^{2}}, s<1
$$

Figure 1(b) shows the lines of equal density, which are circumferences, for Equation (3) with the new variable $s$. Consequently, this study uses the density function for every radial distance $r$ and direction $d$.

$$
\rho(r, d)=\sum_{i=1}^{n}\left(1-\left(\frac{r-r_{i}}{h_{r}}\right)^{2}-\left(\frac{\alpha}{h_{d}}\right)^{2}\right)^{2}
$$

where $\alpha$ is the minimum distance between $\left|d-d_{i}\right|$ and $360-\left|d-d_{i}\right|$ when direction is expressed in degrees and $h_{r}$ and $h_{d}$ are the radial and angular windows, respectively.

\subsection{Determination of trajectory groups}

Having established the density function using Equation (5), an example of its values is presented in grey in Figure 1(c). The procedure followed is based on determining density maxima, whose distance for each direction is represented by the black line in Figure 1(c). The trajectory groups are defined by the density minima in this line. In this example, four minima are found, represented by black dots. Finally, borders of these groups are obtained by increasing (or decreasing) the radial distance from these minima and observing the lowest density in adjacent points. Borders of this example are presented by grey lines in Figure 1(d). As a result, some trajectory groups have little radial extension, such as the group around $180^{\circ}$, and borders may be curved.

\section{Results}

\subsection{Window determination}

One open question inherent to the kernel smoothing procedure is window determination. Silverman (1986) considered an expression for the window that depends on the number and standard deviation of the data.

In order to investigate the behaviour of the kernel function, different pairs of radial and angular windows have been tried and the number of groups for each pair has 
(a)

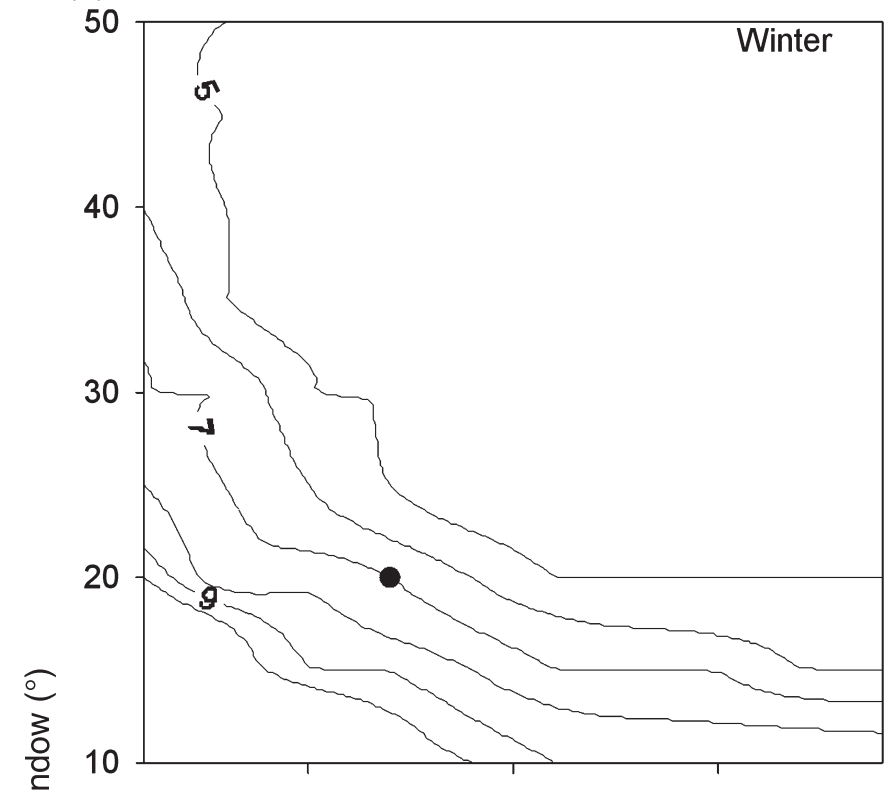

(c)

$\frac{\frac{\pi}{5}}{\frac{C}{4}}$

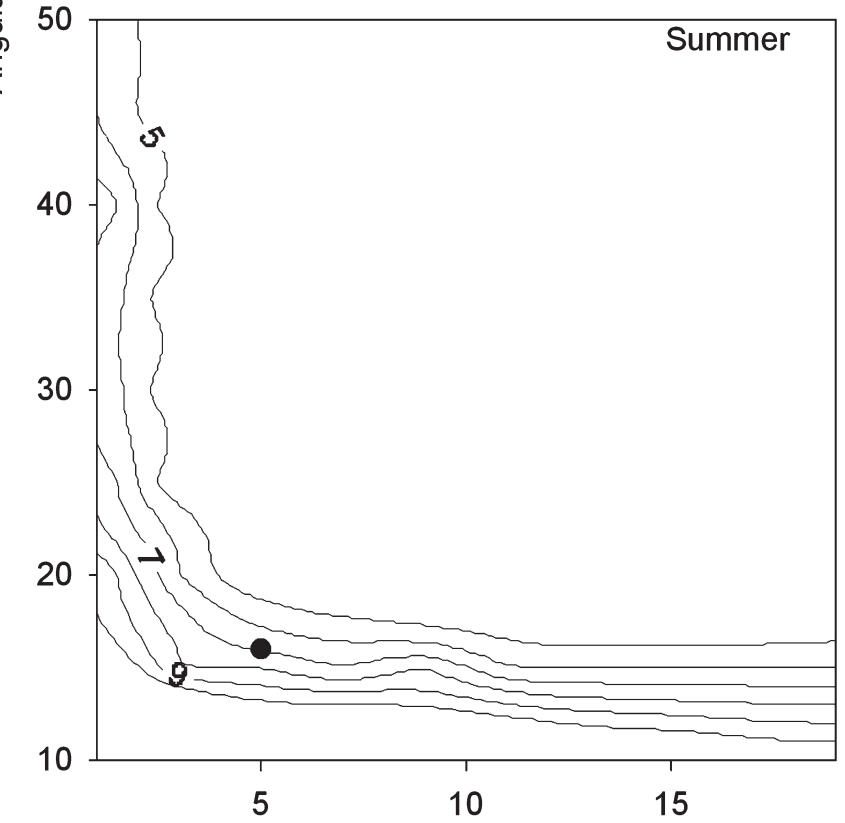

(b)

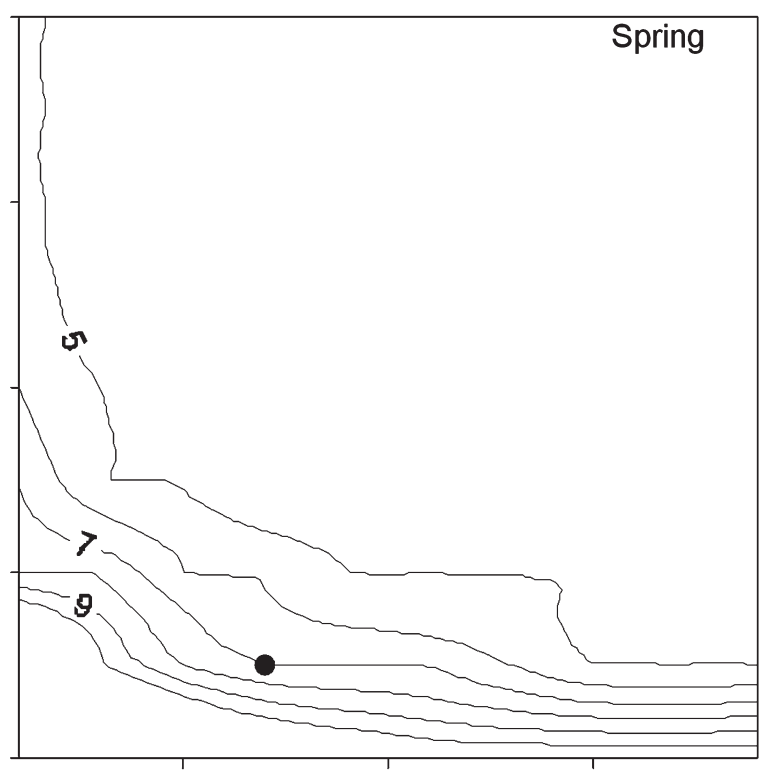

(d)

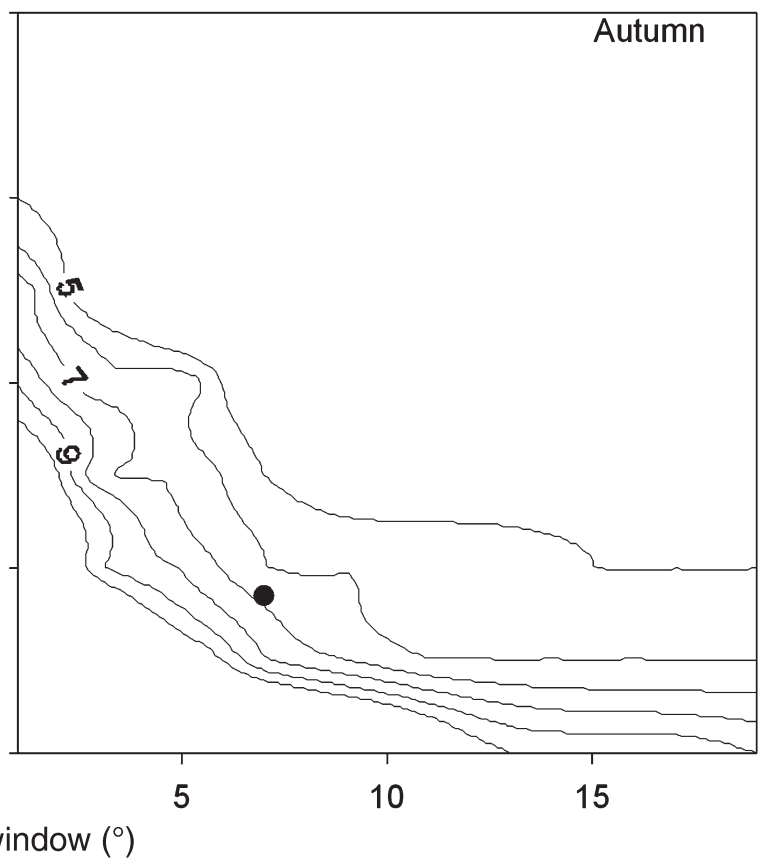

Figure 2. (a)-(d) Contour plots showing the number of minima for different values of the angular and radial windows. The black dots correspond to the 'knee' of the selected curve for the angular and radial windows chosen.

been obtained. Wide windows are associated with smooth functions, providing a low number of groups. However, irregular shapes and a high number of groups are observed with narrow windows. Because two windows are included in this study, the number of trajectory groups depends on the values of both windows. Figure 2 presents the curves formed joining pairs of windows that determine the same number of groups. Only the interval between five and ten groups was presented because curves are closer when the number of groups increases, and they are more separated or even irregular when the number of groups is small. Curves are L-shaped, revealing insensitivity to one of the windows (the same number of groups is obtained for the same or similar values of one window although with an interval of values from the other window). This insensitivity is noticeable for the radial window, e.g. in summer, Figure 2(c), when angular window changes around by two degrees for radial windows above five degrees, but less marked for the angular window. Seasonal analysis is justified to consider the annual evolution of air trajectories, which, in fact, are meteorological variables subject to seasonal changes.

As a result of this analysis, the exact number of trajectory groups is not firmly established; instead, an interval 
(a)

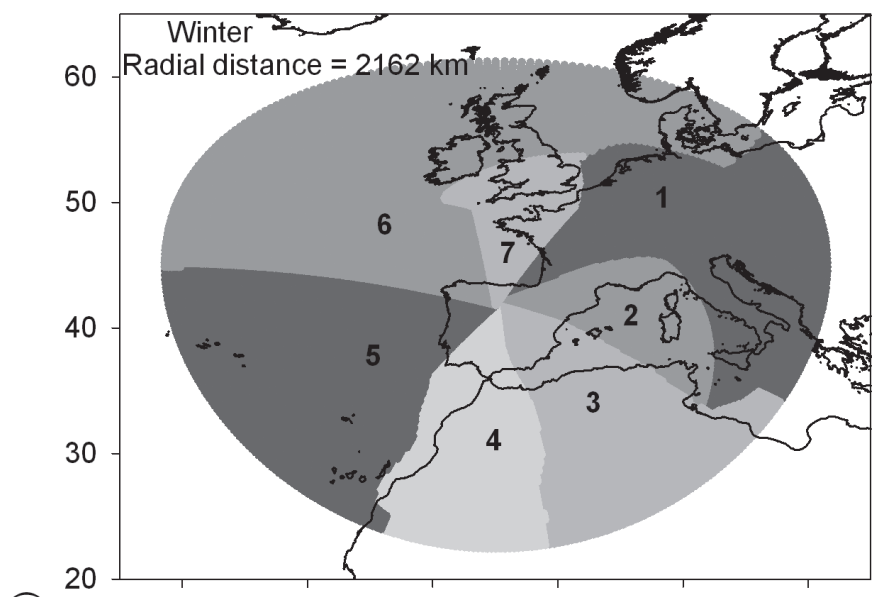

o

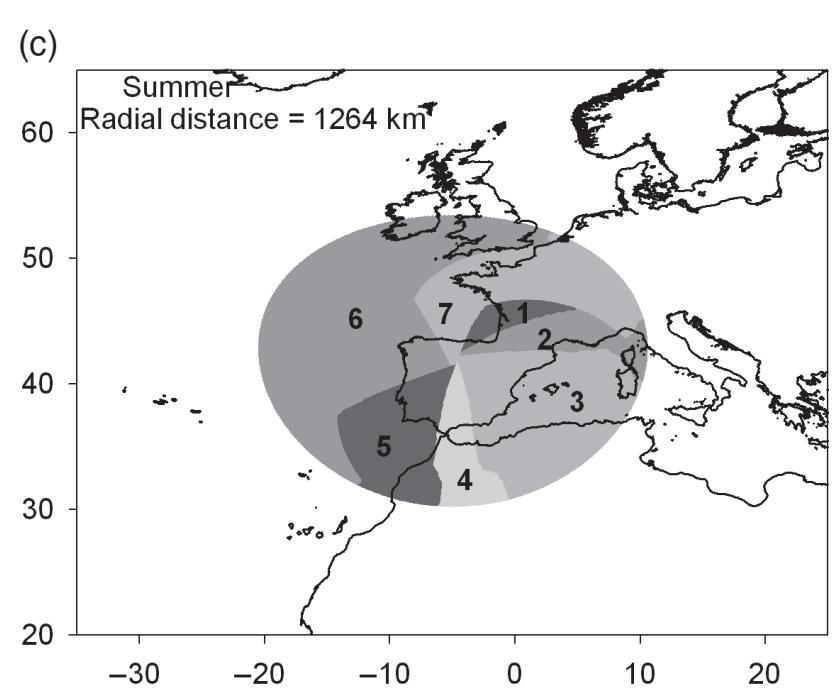

(b)

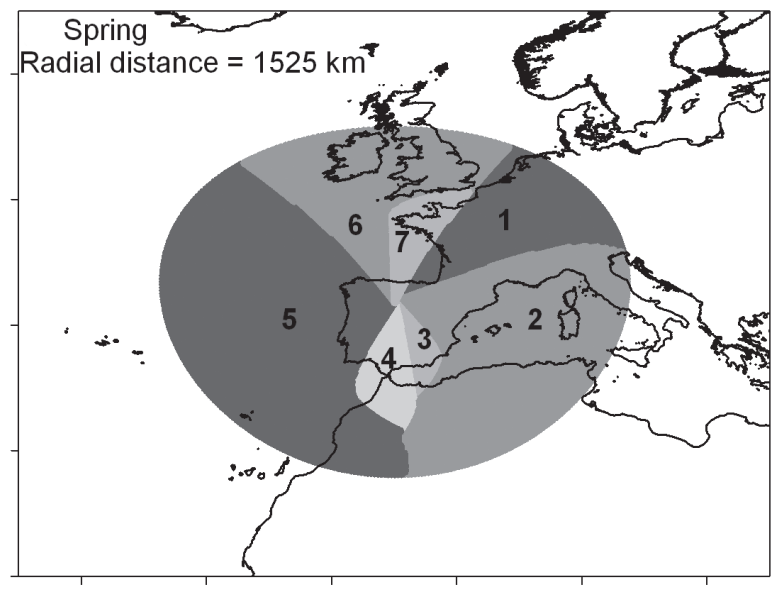

(d)

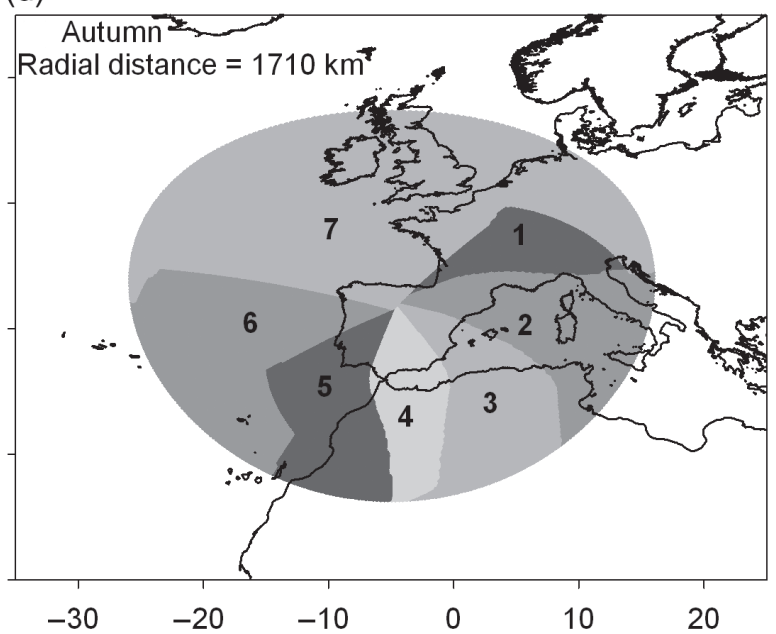

Figure 3. (a)-(d) Distribution of the regions linked to the groups of trajectory centroids formed from the minima of the density function. Radial distances correspond to $75 \%$ of the centroids closest to the measurement site.

is suggested. This result is in agreement with the varied number of trajectory groups employed using procedures other than the one used in this study (Pérez et al., 2015b). In this article, seven groups were considered because the corresponding curve may be observed as the frontier between two regions. Above it, curves are separated, and below it curves are closer together in spring and autumn.

Once the number of groups is established, windows must be determined. Figure 2 indicates that the best choice seems to be intermediate window values, which correspond to a point near the 'knee' of the curve, i.e. the region where the trend changes. The same radial window $\left(7^{\circ}\right)$ was proposed for winter, spring and autumn to simplify treatment. However, a slightly different radial window $\left(5^{\circ}\right)$ was considered for summer to approximate the point to the curve 'knee'. Angular windows were placed between 15 and $20^{\circ}$.

\subsection{Trajectory sectors}

The spatial extent of groups formed with the windows proposed may be observed in Figure 3. Radial distance considers $75 \%$ of trajectory centroids in each season. The angular spread of the groups is varied and some are closed within the region presented. Oceanic influence plays a major role due to the location of the measurement site. The greatest radial extent corresponds to winter, and the minimum to summer, attributed to the contrasting winds observed in the two seasons. A noticeable contraction is observed in spring because three groups are confined in the region presented.

In order to obtain a quantitative description of the groups, Table 1 presents simple statistics of centroids in these seasons. Markou and Kassomenos (2010) and Dimitriou and Kassomenos (2013) used length scales to classify trajectory range. This article considers three intervals for radial distance to investigate the groups formed.

- Short range: radial distance $<500 \mathrm{~km}$,

- Medium range: $500 \mathrm{~km}<$ radial distance $<1000 \mathrm{~km}$,

- Long range: $1000 \mathrm{~km}<$ radial distance. 
Table 1. Seasonal values of frequencies (trajectory percentage) and statistics of radial distance and direction for the groups formed.

\begin{tabular}{|c|c|c|c|c|c|c|}
\hline \multirow[t]{2}{*}{ Season } & \multirow[t]{2}{*}{ Group } & \multirow[t]{2}{*}{ Frequency (\%) } & \multicolumn{2}{|c|}{ Radial distance $(\mathrm{km})$} & \multicolumn{2}{|c|}{ Direction $\left(^{\circ}\right)$} \\
\hline & & & Average & Stand. dev. & Average & Stand. dev. \\
\hline \multirow[t]{7}{*}{ Winter } & 1 & 7.1 & 1179 & 528 & 46 & 13 \\
\hline & 2 & 4.3 & 705 & 280 & 83 & 14 \\
\hline & 3 & 4.1 & 534 & 298 & 139 & 16 \\
\hline & 4 & 4.4 & 704 & 315 & 196 & 12 \\
\hline & 5 & 30.7 & 1503 & 652 & 263 & 16 \\
\hline & 6 & 44.5 & 2052 & 871 & 313 & 25 \\
\hline & 7 & 4.8 & 734 & 277 & 7 & 10 \\
\hline \multirow[t]{7}{*}{ Spring } & 1 & 8.7 & 728 & 344 & 39 & 10 \\
\hline & 2 & 12.4 & 560 & 250 & 105 & 23 \\
\hline & 3 & 2.0 & 394 & 152 & 155 & 7 \\
\hline & 4 & 2.4 & 388 & 194 & 188 & 9 \\
\hline & 5 & 56.1 & 1392 & 718 & 280 & 27 \\
\hline & 6 & 13.7 & 1086 & 440 & 347 & 12 \\
\hline & 7 & 4.8 & 595 & 203 & 11 & 6 \\
\hline \multirow[t]{7}{*}{ Summer } & 1 & 5.1 & 335 & 172 & 32 & 10 \\
\hline & 2 & 2.5 & 298 & 158 & 64 & 7 \\
\hline & 3 & 11.3 & 357 & 167 & 123 & 22 \\
\hline & 4 & 3.1 & 291 & 142 & 181 & 8 \\
\hline & 5 & 7.6 & 470 & 228 & 220 & 14 \\
\hline & 6 & 61.2 & 1151 & 575 & 297 & 25 \\
\hline & 7 & 9.2 & 430 & 209 & 360 & 13 \\
\hline \multirow[t]{7}{*}{ Autumn } & 1 & 3.0 & 781 & 367 & 49 & 8 \\
\hline & 2 & 5.0 & 654 & 449 & 88 & 13 \\
\hline & 3 & 6.0 & 596 & 374 & 132 & 12 \\
\hline & 4 & 6.9 & 534 & 244 & 171 & 13 \\
\hline & 5 & 9.4 & 777 & 382 & 218 & 13 \\
\hline & 6 & 20.9 & 1117 & 463 & 261 & 16 \\
\hline & 7 & 48.7 & 1601 & 817 & 322 & 34 \\
\hline
\end{tabular}

As regards radial distance, spring is the season with the most varied trajectories. Groups 3 and 4 correspond to short range, with their direction being around the south and their frequencies being low. Medium range is linked to groups 1, 2 and 7. Their directions extend from around north to east or even south and their frequencies are also intermediate, between around 5 and 12\%. Groups 5 and 6 are associated with long range. The directions of these trajectories are very varied because frequencies are high, although with a westerly component. Trajectories are contrasted for the summer season because group 6, which presents a high frequency and a westerly direction, corresponds to long range and the rest to short range. Winter and autumn were quite similar.

Distances are less balanced in autumn where the range is long for two groups that display the greatest frequencies and a mainly westerly component, whereas the range is medium for the remaining five groups. In winter, distances are more balanced with three groups of long range and four groups of medium range.

In general, long range is linked to air trajectories mainly from the Atlantic Ocean and, second, from central northern Europe, whereas short range is associated with trajectories from the south. The average coefficient of variation is around 0.47 for the radial distance, revealing that air trajectories may vary enormously in each group. Standard deviation of directions, calculated following Donnelly
Table 2. Coefficients of Equation (1) together with the correlation coefficient, $R$, for the levels investigated.

\begin{tabular}{lcccc}
\hline Gas & Level $(\mathrm{m})$ & $A(\mathrm{ppm})$ & $B\left(\mathrm{ppm}\right.$ year $\left.^{-1}\right)$ & $R$ \\
\hline $\mathrm{CO}_{2}$ & 1.8 & 398.38 & 2.40 & 0.272 \\
& 3.7 & 397.41 & 2.35 & 0.321 \\
$\mathrm{CH}_{4}$ & 8.3 & 396.30 & 2.28 & 0.394 \\
& 1.8 & 1.8859 & 0.0085 & 0.227 \\
& 3.7 & 1.8867 & 0.0085 & 0.223 \\
& 8.3 & 1.8870 & 0.0085 & 0.227 \\
\hline
\end{tabular}

et al. (2011), is around $15^{\circ}$, which means that directions present small variations.

Similar analyses are not usual. However, in order to compare this result with previous studies, Hernández-Ceballos et al. (2016) analysed heat-wave events and showed the prevalence of westerly circulation over the northern Iberian Peninsula, attributing this flow to the peninsula's orography. Pérez et al. (2015b) presented a cluster analysis with 24-h backwards trajectories at the same measurement site where trajectories from the ocean are longer and more frequent than those over land. Moreover, the seasonal evolution of the trajectory spatial extent is in agreement with that obtained in this study. Notario et al. (2014) considered a cluster analysis of 48-h backwards trajectories at different sites in the southern plateau of the Iberian 
(a)

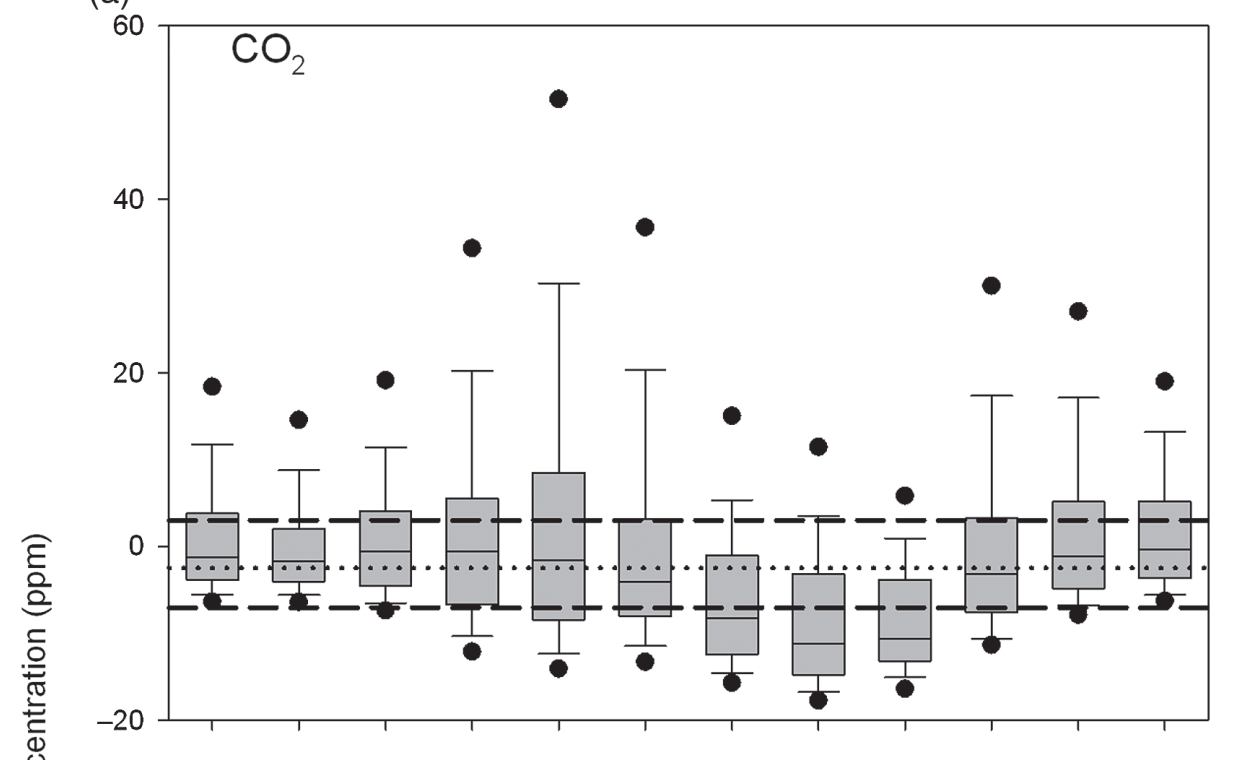

(b)

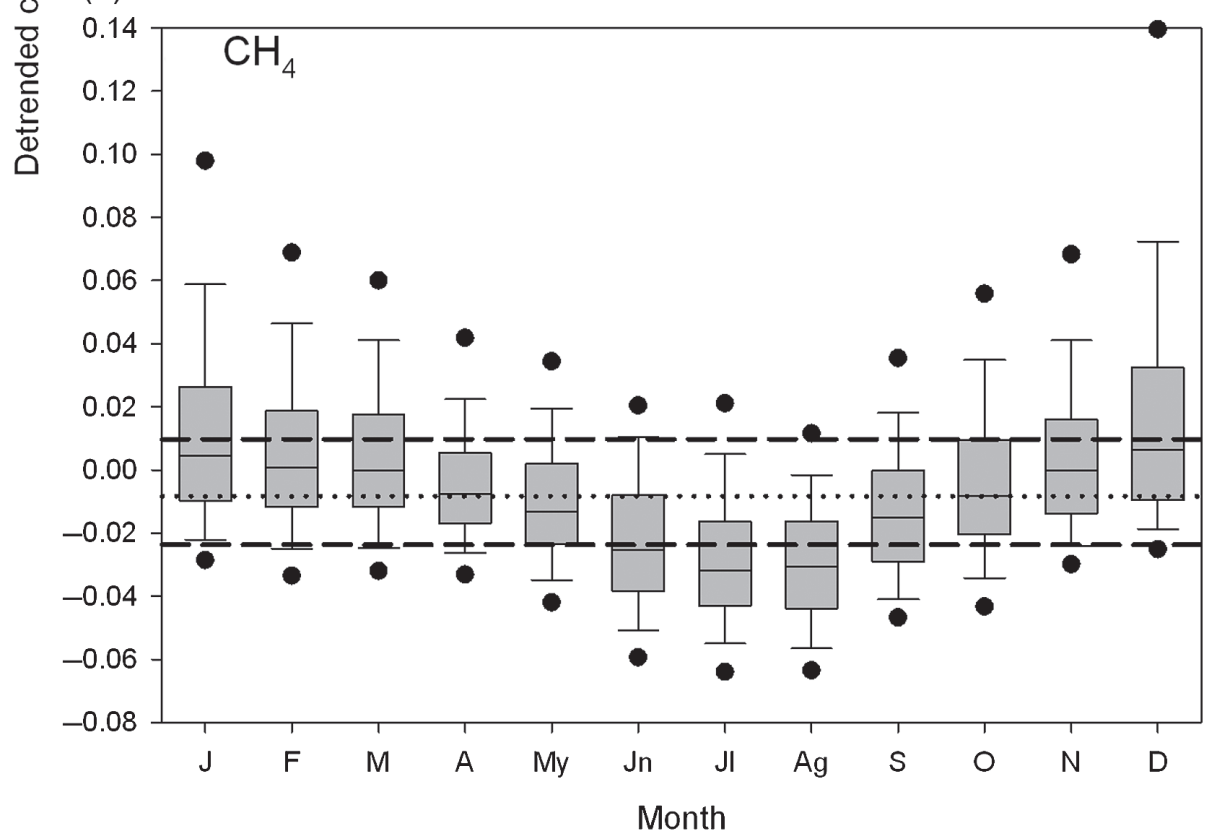

Figure 4. (a) and (b) Annual evolution of the detrended concentrations for the $1.8 \mathrm{~m}$ level in the boxplot. Dotted line is the median of all observations and dashed lines represent the interquartile range.

Peninsula where the longest trajectories corresponded to air parcels arriving from the ocean.

\section{3. $\mathrm{CO}_{2}$ and $\mathrm{CH}_{4}$ evolution and annual cycle}

Coefficients of Equation (1) were presented in Table 2. This equation reveals that $\mathrm{CO}_{2}$ concentration rose by around $14 \mathrm{ppm}$ during the measurement period, whereas the increase in $\mathrm{CH}_{4}$ was only around $0.051 \mathrm{ppm}$. The

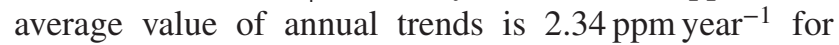
$\mathrm{CO}_{2}$, which is in agreement with those recently obtained at different locations. Fang et al. (2016) presented $\mathrm{CO}_{2}$ trends of 2.7 and 3.8 ppm year $^{-1}$ for two directions of air masses reaching Shangdianzi, China, for the period 2009-2013. Hernández-Paniagua et al. (2015) obtained
2.45 ppm year $^{-1}$ at Egham, UK, in the period 2000-2012, although this rate reached $3.26 \mathrm{ppm} \mathrm{year}^{-1}$ for the $\mathrm{W}$ sector, and Timokhina et al. (2015) observed 2.02 ppm year $^{-1}$ in central Siberia, Russia, in 2006-2013. For $\mathrm{CH}_{4}$, the annual rate was $0.0085 \mathrm{ppm}_{\text {year }}{ }^{-1}$, in agreement with values of 0.006 and $0.010 \mathrm{ppm}_{\text {year }}{ }^{-1}$ presented by Fang et al. (2016) or by Vermeulen et al. (2011), who recorded a value of 0.0074 ppm year $^{-1}$ at Cabaw, The Netherlands, for the period 2005-2010.

The influence of trend on the annual cycle is negligible when the period analysed is short. However, the trend weight increases with long periods. The annual evolution of detrended concentrations is presented for the $1.8 \mathrm{~m}$ level in Figure 4, where the box corresponds to the interquartile 
Table 3. Coefficients of Equation (1) and correlation coefficient, $R$, for the groups established in the seasonal analysis of the $1.8 \mathrm{~m}$ level.

\begin{tabular}{|c|c|c|c|c|c|c|c|}
\hline \multirow[t]{2}{*}{ Season } & \multirow[t]{2}{*}{ Group } & \multicolumn{3}{|c|}{$\mathrm{CO}_{2}$} & \multicolumn{3}{|c|}{$\mathrm{CH}_{4}$} \\
\hline & & $A(\mathrm{ppm})$ & $B\left(\right.$ ppm year $\left.^{-1}\right)$ & $R$ & $A(\mathrm{ppm})$ & $B\left(\right.$ ppm year $\left.^{-1}\right)$ & $R$ \\
\hline \multirow[t]{7}{*}{ Winter } & 1 & 402.05 & 2.38 & 0.481 & 1.9167 & 0.0093 & 0.343 \\
\hline & 2 & 404.61 & 2.13 & 0.328 & 1.9365 & 0.0051 & 0.121 \\
\hline & 3 & 403.03 & 2.86 & 0.362 & 1.9186 & 0.0122 & 0.321 \\
\hline & 4 & 400.13 & 3.71 & 0.549 & 1.9150 & 0.0180 & 0.274 \\
\hline & 5 & 400.42 & 1.73 & 0.351 & 1.8981 & 0.0066 & 0.151 \\
\hline & 6 & 399.04 & 2.11 & 0.413 & 1.8880 & 0.0101 & 0.303 \\
\hline & 7 & 400.90 & 3.42 & 0.469 & 1.9262 & 0.0114 & 0.097 \\
\hline \multirow[t]{7}{*}{ Spring } & 1 & 398.39 & 3.08 & 0.218 & 1.8965 & 0.0071 & 0.372 \\
\hline & 2 & 405.50 & 1.41 & 0.118 & 1.8818 & 0.0111 & 0.347 \\
\hline & 3 & 413.48 & -0.10 & -0.006 & 1.8840 & 0.0060 & 0.180 \\
\hline & 4 & 402.62 & 3.82 & 0.302 & 1.8905 & 0.0111 & 0.226 \\
\hline & 5 & 402.44 & 2.03 & 0.169 & 1.8687 & 0.0098 & 0.418 \\
\hline & 6 & 398.24 & 2.65 & 0.253 & 1.8832 & 0.0088 & 0.541 \\
\hline & 7 & 394.49 & 3.08 & 0.276 & 1.8819 & 0.0125 & 0.293 \\
\hline \multirow[t]{7}{*}{ Summer } & 1 & 389.27 & 3.39 & 0.493 & 1.8815 & 0.0057 & 0.339 \\
\hline & 2 & 390.02 & 2.87 & 0.394 & 1.9057 & -0.0014 & -0.083 \\
\hline & 3 & 398.06 & 2.46 & 0.282 & 1.8669 & 0.0095 & 0.280 \\
\hline & 4 & 396.99 & 3.02 & 0.238 & 1.8641 & 0.0085 & 0.348 \\
\hline & 5 & 391.57 & 4.07 & 0.399 & 1.8617 & 0.0089 & 0.284 \\
\hline & 6 & 388.83 & 2.85 & 0.429 & 1.8510 & 0.0115 & 0.542 \\
\hline & 7 & 387.65 & 3.40 & 0.584 & 1.8640 & 0.0100 & 0.638 \\
\hline \multirow[t]{7}{*}{ Autumn } & 1 & 405.00 & 0.91 & 0.145 & 1.8879 & 0.0159 & 0.557 \\
\hline & 2 & 396.03 & 2.58 & 0.406 & 1.8958 & 0.0087 & 0.272 \\
\hline & 3 & 402.47 & 4.52 & 0.362 & 1.9241 & 0.0086 & 0.111 \\
\hline & 4 & 402.85 & 2.31 & 0.311 & 1.9284 & 0.0089 & 0.111 \\
\hline & 5 & 399.23 & 3.11 & 0.443 & 1.8791 & 0.0171 & 0.378 \\
\hline & 6 & 399.85 & 2.49 & 0.290 & 1.8904 & 0.0088 & 0.201 \\
\hline & 7 & 397.93 & 2.13 & 0.330 & 1.8916 & 0.0081 & 0.204 \\
\hline
\end{tabular}

range, with the median being the line inside the box, and the whiskers extending from the 10th to the 90th percentiles, and isolated dots indicating the 5th and 95th percentiles. Moreover, the median of all data is represented by the dotted line, and the first and third quartiles by the dashed lines. Half of the observations are confined in a narrow interval, around $10.1 \mathrm{ppm}$, for $\mathrm{CO}_{2}$. The yearly cycle is scarcely evident because monthly medians are confined mainly to the narrow interquartile range of all observations and are close to the median of all observations. The lowest $\mathrm{CO}_{2}$ median is reached in August, which may be explained by the scant vegetation activity in summer, when vegetation dies in this region, together with the high atmospheric dispersion linked to the high temperatures and dilution in the boundary layer that is well developed (Pérez et al., 2016). July and September medians are also below the first quartile of all observations. One prominent feature is the contrasting values reached in spring, especially in May, when the highest values are observed. These may be explained by the vegetation growth that is noticeably active in this season in this region and which determines high $\mathrm{CO}_{2}$ concentrations during the night, when the boundary layer height records its lowest daily values and dispersion is inhibited. As regards $\mathrm{CH}_{4}$, half of the observations are confined in an interval of $0.033 \mathrm{ppm}$. Its cycle is simpler because it only presents one minimum in July attributed to oxidation with the hydroxyl radical in the troposphere
(Sánchez et al., 2014), together with intensive dispersion in summer, and one maximum in December. For this gas, June and August medians are also below the first quartile of all observations. Looking at the location of the monthly medians, the annual quartiles and the annual median, the cycle is more marked for $\mathrm{CH}_{4}$ than for $\mathrm{CO}_{2}$.

\subsection{Relationship between trajectory groups and trace gases}

$\mathrm{CO}_{2}$ and $\mathrm{CH}_{4}$ evolution is affected by various factors such as sources, sinks and atmospheric dynamics (Sánchez et al., 2010; García et al., 2016). Consequently, establishing a direct relationship between the concentration recorded and each factor is not easy. Air trajectories are only one of the different meteorological variables that influence the concentration of both gases. Long straight trajectories imply high wind speed, whereas short or highly curved trajectories are associated with low wind speed. This section presents the transport influence on concentrations measured by conducting a comparison among the values obtained for the previously defined groups.

First, the trends for the groups proposed have been calculated. Table 3 presents coefficients of Equation (1) for the lowest level. Their values are very varied because concentrations depend on season and group. A noticeable $\mathrm{CO}_{2}$ trend was obtained in summer because the average for all the groups was around 3.2 ppm year $^{-1}$, 
Table 4. Averages and their standard deviations of detrended concentrations at the $1.8 \mathrm{~m}$ level, NDVI and population density, together with the corresponding fraction of surface with data for the trajectory groups proposed.

\begin{tabular}{|c|c|c|c|c|c|c|c|c|c|c|c|}
\hline \multirow[t]{2}{*}{ Season } & \multirow[t]{2}{*}{ Group } & \multicolumn{2}{|c|}{$\mathrm{CO}_{2}(\mathrm{ppm})$} & \multicolumn{2}{|c|}{$\mathrm{CH}_{4}(\mathrm{ppm})$} & \multicolumn{3}{|c|}{ NDVI } & \multicolumn{3}{|c|}{ Population density (persons km${ }^{-2}$ ) } \\
\hline & & Average & $\begin{array}{l}\text { Standard } \\
\text { dev. }\end{array}$ & Average & $\begin{array}{c}\text { Standard } \\
\text { dev. }\end{array}$ & Average & $\begin{array}{c}\text { Standard } \\
\text { dev. }\end{array}$ & $\begin{array}{c}\text { Frac. of } \\
\text { surface } \%\end{array}$ & Average & $\begin{array}{l}\text { Standard } \\
\text { dev. }\end{array}$ & $\begin{array}{c}\text { Frac. of } \\
\text { surface } \%\end{array}$ \\
\hline \multirow[t]{7}{*}{ Winter } & 1 & 3.61 & 8.02 & 0.0329 & 0.0471 & 0.4382 & 0.1183 & 75.20 & 164.1 & 376.9 & 72.69 \\
\hline & 2 & 5.53 & 9.54 & 0.0419 & 0.0658 & 0.4616 & 0.1593 & 44.04 & 104.1 & 370.8 & 40.19 \\
\hline & 3 & 5.36 & 12.16 & 0.0384 & 0.0595 & 0.1762 & 0.1228 & 85.71 & 30.9 & 203.2 & 84.76 \\
\hline & 4 & 4.65 & 10.33 & 0.0500 & 0.1136 & 0.1972 & 0.1716 & 81.75 & 27.6 & 133.1 & 80.78 \\
\hline & 5 & 0.35 & 7.92 & 0.0073 & 0.0733 & 0.4753 & 0.1963 & 4.54 & 117.6 & 488.6 & 3.98 \\
\hline & 6 & -0.15 & 7.18 & 0.0067 & 0.0492 & 0.4380 & 0.1610 & 13.12 & 87.5 & 275.0 & 10.76 \\
\hline & 7 & 4.72 & 10.47 & 0.0465 & 0.1884 & 0.5745 & 0.1149 & 44.02 & 267.3 & 610.5 & 38.80 \\
\hline \multirow[t]{7}{*}{ Spring } & 1 & 1.69 & 20.24 & 0.0072 & 0.0260 & 0.6639 & 0.1086 & 87.76 & 192.6 & 458.6 & 86.25 \\
\hline & 2 & 4.77 & 21.56 & 0.0021 & 0.0544 & 0.3386 & 0.2195 & 66.80 & 80.4 & 304.2 & 64.47 \\
\hline & 3 & 8.14 & 26.28 & -0.0089 & 0.0505 & 0.3686 & 0.1003 & 78.04 & 106.5 & 484.5 & 74.91 \\
\hline & 4 & 7.55 & 24.33 & 0.0106 & 0.0956 & 0.4002 & 0.1275 & 74.67 & 94.0 & 241.2 & 72.14 \\
\hline & 5 & 2.88 & 19.70 & -0.0130 & 0.0355 & 0.3424 & 0.2153 & 14.56 & 72.3 & 314.7 & 14.11 \\
\hline & 6 & 0.75 & 16.22 & -0.0016 & 0.0220 & 0.6572 & 0.1186 & 33.15 & 226.7 & 550.3 & 28.66 \\
\hline & 7 & -1.69 & 16.98 & 0.0087 & 0.0646 & 0.6245 & 0.1136 & 31.35 & 106.4 & 221.1 & 25.50 \\
\hline \multirow[t]{7}{*}{ Summer } & 1 & -6.14 & 10.86 & -0.0130 & 0.0286 & 0.6279 & 0.1170 & 68.69 & 70.9 & 254.3 & 66.41 \\
\hline & 2 & -7.00 & 11.01 & -0.0090 & 0.0327 & 0.6136 & 0.1368 & 75.90 & 93.6 & 315.6 & 71.54 \\
\hline & 3 & -0.11 & 14.81 & -0.0162 & 0.0574 & 0.2681 & 0.1435 & 57.85 & 88.4 & 393.0 & 55.44 \\
\hline & 4 & 0.64 & 19.25 & -0.0219 & 0.0356 & 0.2392 & 0.1208 & 91.52 & 62.5 & 159.5 & 89.72 \\
\hline & 5 & -1.43 & 15.57 & -0.0230 & 0.0491 & 0.3264 & 0.1372 & 34.24 & 100.5 & 396.5 & 32.93 \\
\hline & 6 & -8.28 & 10.12 & -0.0264 & 0.0305 & 0.6296 & 0.1291 & 14.70 & 222.9 & 586.6 & 13.22 \\
\hline & 7 & -7.76 & 9.31 & -0.0175 & 0.0234 & 0.6293 & 0.1136 & 65.22 & 173.9 & 508.0 & 62.89 \\
\hline \multirow[t]{7}{*}{ Autumn } & 1 & 2.68 & 10.74 & 0.0216 & 0.0415 & 0.5394 & 0.1317 & 95.35 & 128.4 & 321.2 & 94.24 \\
\hline & 2 & -1.87 & 10.43 & 0.0103 & 0.0549 & 0.4465 & 0.1903 & 45.41 & 114.9 & 378.8 & 40.85 \\
\hline & 3 & 10.56 & 20.62 & 0.0386 & 0.1343 & 0.1877 & 0.1252 & 83.54 & 44.0 & 263.1 & 82.57 \\
\hline & 4 & 4.21 & 12.04 & 0.0436 & 0.1367 & 0.2511 & 0.1586 & 87.52 & 49.1 & 186.1 & 85.90 \\
\hline & 5 & 2.87 & 12.38 & 0.0177 & 0.0838 & 0.2607 & 0.1904 & 44.59 & 57.0 & 284.6 & 43.41 \\
\hline & 6 & 1.73 & 14.28 & 0.0053 & 0.0742 & 0.5889 & 0.1089 & 3.54 & 142.4 & 409.1 & 3.29 \\
\hline & 7 & -1.03 & 10.69 & 0.0048 & 0.0677 & 0.5636 & 0.1110 & 32.02 & 211.3 & 486.7 & 29.37 \\
\hline
\end{tabular}

Bold numbers correspond to the first tercile and italics to the third tercile.

compared to only $2.3 \mathrm{ppm}_{\text {year }}{ }^{-1}$ in spring. However, the most accentuated trend was observed for group 3

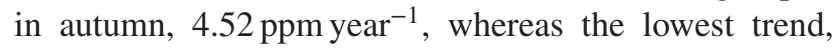
$-0.10 \mathrm{ppm}$ year $^{-1}$, was for group 3 in spring, although its $R$ reveals no linear trend, and frequencies of both groups are small. For $\mathrm{CH}_{4}$, the highest average was obtained in autumn, 0.0109 ppm year $^{-1}$ closely followed by winter, whereas the lowest corresponded to summer, $0.0075 \mathrm{ppm}_{\text {year }}{ }^{-1}$. Prominent were group 4 in winter, with a trend of $0.0180 \mathrm{ppm}_{\text {year }}{ }^{-1}$, and group 2 in summer, with -0.0014 ppm year $^{-1}$, the latter also displaying a low $R$. In both cases, there were low frequencies.

Table 4 shows the average concentrations and their standard deviations for the trajectory groups at the lowest level measured. Because observations were detrended, standard deviations are similar or even greater than averages. Fisher's least significance difference method was applied to observations. Over 21 concentration differences may be calculated in each season. Around 16 were statistically significant for $\mathrm{CO}_{2}$ and 15 for $\mathrm{CH}_{4}$, which is a moderately satisfactory result.

Average NDVI was calculated in order to link $\mathrm{CO}_{2}$ concentration to vegetation. The seasonal evolution is presented in Figure 5, which may be interpreted following Table 5 (Institut Cartogràfic i Geològic de Catalunya
(ICGC), 2017). In most of Europe, the highest values were reached in spring. After this season, they gradually decreased until reaching the lowest values observed in winter, the sharpest change being from winter to spring. However, most of the Iberian Peninsula follows a different pattern. The most pronounced transition was observed between spring, when the highest NDVI is recorded, and summer, when the lowest values are obtained. After summer, NDVI gradually increased until spring. Moderate-Resolution Imaging Spectroradiometer (MODIS) values at the measurement site confirmed this pattern (Pérez et al., 2016). Table 4 includes the NDVI average for each trajectory group, together with the standard deviation and the fraction of sites with vegetation. The correlation between $\mathrm{CO}_{2}$ and NDVI from Table 4 presents a coefficient of -0.592 , which is statistically significant at a $0.1 \%$ confidence level. This result reveals vegetation as a $\mathrm{CO}_{2}$ sink. However, sea surface is excluded from NDVI. The negative correlation between $\mathrm{CH}_{4}$ and NDVI is noticeably weaker, although a statistically significant coefficient at a $5 \%$ confidence level is obtained when one of the following outliers is suppressed, group 7 in winter or group 4 in summer, with high and low NDVIs, respectively.

Figure 6 shows the population density, which is high in western Europe, although very low in a noticeable part of the Iberian Peninsula. Another prominent feature is 
(a)

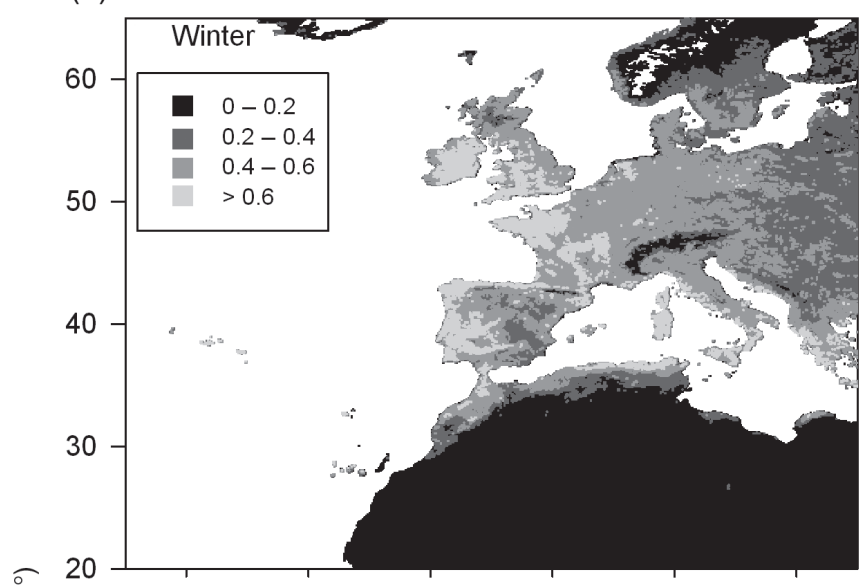

(c)

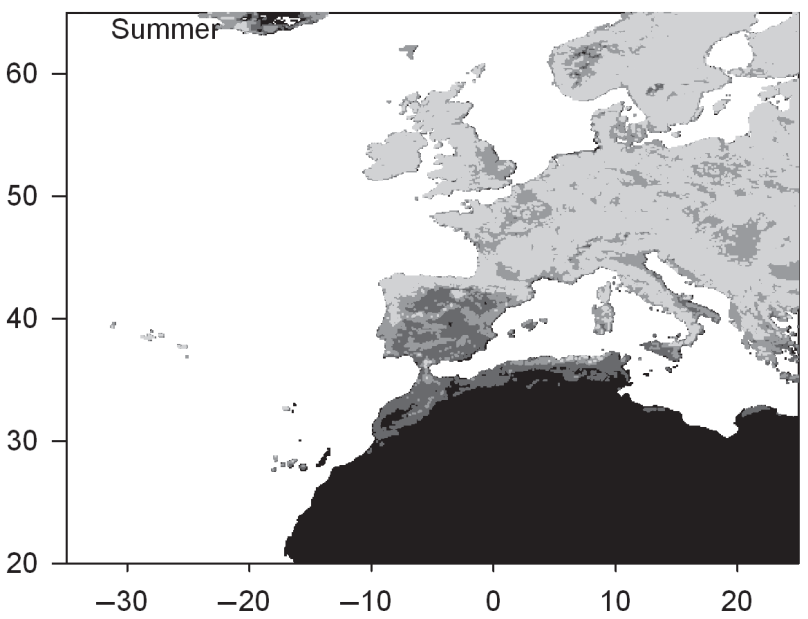

(b)

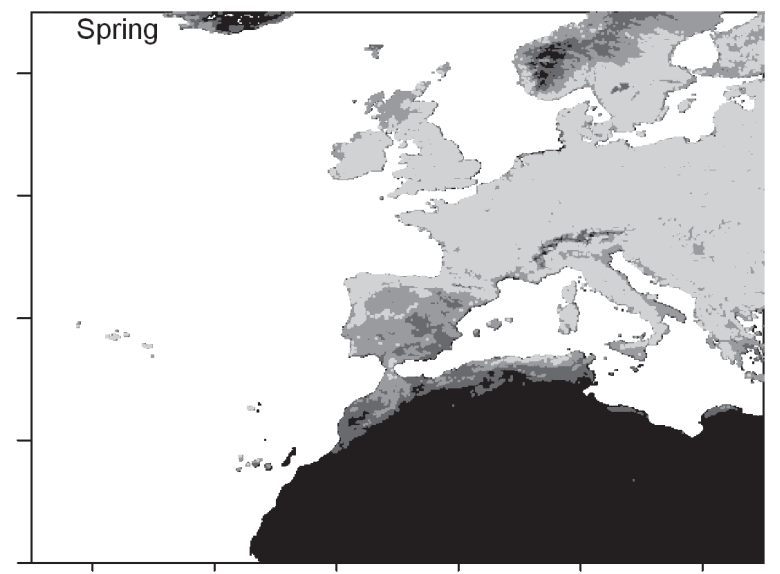

(d)

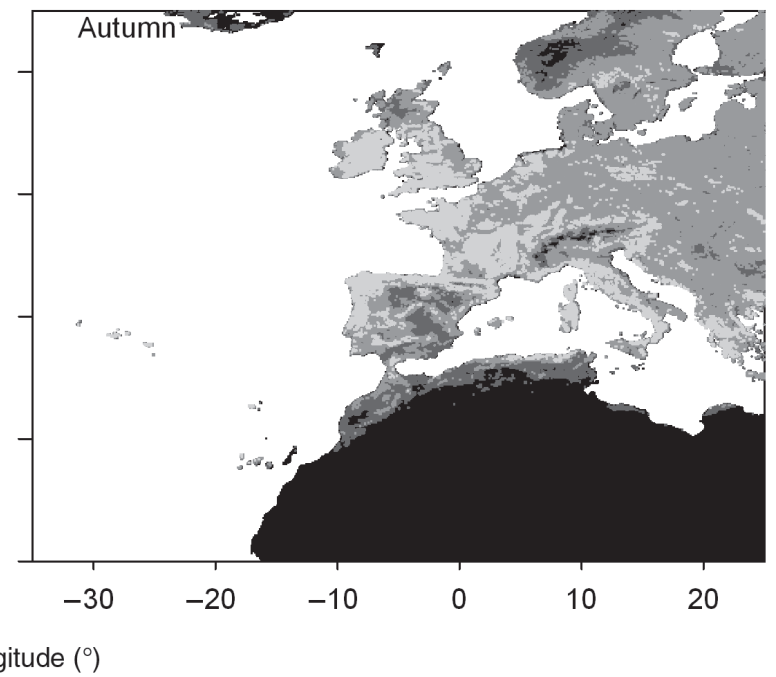

Figure 5. (a)-(d) Seasonal evolution of the NDVI in the region studied.

the large population density observed at a strip in North Africa, which may act as a relevant $\mathrm{CO}_{2}$ source. Table 4 also presents the population density average for each group together with the standard deviation and the fraction of sites with value. Standard deviations are greater than averages due to the major density variations in each group. The fraction of sites with value is slightly greater for NDVI. The correlation between NDVI and population density for the values in Table 4 shows satisfactory agreement, with a coefficient of 0.753 , revealing an increasing relationship between vegetation and population density. The negative correlation between $\mathrm{CO}_{2}$ and population density is statistically significant at a 5\% level when the outlier corresponding to group 7 in winter is suppressed. This result suggests that the sink formed by vegetation prevails over the population density source. A similar behaviour was observed for $\mathrm{CH}_{4}$ and population density although in this case the second outlier corresponding to group 4 in summer should be removed in order to obtain a statistically significant correlation at a $5 \%$ level.

The $\mathrm{CO}_{2}$ concentration may be explained by adding the NDVI and population together with the information about air parcel trajectories. Terciles of concentration, NDVI and population density in Table 4 were calculated each season so as to divide the values into high, medium and low quantities. Following these terciles, groups 3 and 4 in winter and 3,4 and 5 in summer and autumn are linked to low NDVI and high $\mathrm{CO}_{2}$ because they correspond to air trajectories from North Africa, where population is relevant although its density is low because it is spread unevenly. Groups 3 and 4 in spring were associated with high $\mathrm{CO}_{2}$ and moderate NDVI. They present a similar direction, also from North Africa, although they are confined to a short distance where stagnation may play a noticeable role. Moreover, the influence of cities located southeast of the measurement site, such as Valladolid (with a little over 300000 inh. and some $25 \mathrm{~km}$ away) and Madrid (over $3000000 \mathrm{inh}$. and some $185 \mathrm{~km}$ away) should be taken into account, although quantifying this influence would not appear to be easy. Despite the large NDVI, much of the $\mathrm{CO}_{2}$ concentration may be attributed to population density in groups 2 and 7 in winter or group 1 in spring, which correspond to air trajectories from Europe. The influence of vegetation is noticeable in the low $\mathrm{CO}_{2}$ observed in groups 6 and 7 in 
spring together with groups 1, 2 and 7 in summer. Finally, the Atlantic origin of certain trajectories is associated with small concentrations, such as those observed in groups 5 in winter and spring, 6 in winter and summer, and 6 and 7 in autumn. This result is in agreement with $\mathrm{CO}_{2}$ observations presented by García et al. (2012), who described these trajectories with a westerly component at the measurement site as being 'clean wind directions'.

For $\mathrm{CH}_{4}$, the highest concentration seemed to be linked with populated areas in Europe, such as group 7 in winter and spring or group 1 in spring, mainly the Iberian Peninsula with group 3 in summer, or North Africa, group 4 in winter, spring and autumn. However, local contributions other than cities, such as a landfill, should not be ignored, because contrasting concentrations are obtained in groups 3 and 4 in spring, which present a similar direction and extension. In contrast, the smallest concentrations are generally associated with air trajectories from the Atlantic Ocean, such as group 5 in winter, spring and summer, group 6 in winter, summer and autumn, and group 7 in autumn.

Because the analysis of gas transport considered in this article is not common, the oceanic influence of air trajectories will be compared with a few other studies using different substances. Xu et al. (2013) observed that mercury in particulate matter in some southeastern coastal cities of China was diluted in summer by air masses from the ocean. Srivastava et al. (2015) obtained a lower ozone level for marine air reaching Hyderabad, India. In contrast, Donnelly et al. (2015) highlighted the influence of air recirculation on the high $\mathrm{NO}_{2}$ and $\mathrm{PM}_{10}$ levels recorded in Ireland.

\section{Conclusions}

This article presents an original procedure to obtain trajectory groups by calculating the kernel density of the air trajectory centroids described by the radial distance to the measuring site and the direction. Different radial and angular windows were proposed and their corresponding number of groups was calculated.

Although determining the optimal number of groups is not easy, an intermediate number, seven, was selected to investigate the main feature of the procedure, obtaining sectors, not only with varied angular width, but also with different radial extension. Windows were proposed following a graphical procedure by a balance between radial and angular variables.

A seasonal evolution was obtained where the radial extent was considerably greater for winter than for summer, when wind speeds were lower. The highest frequencies corresponded to trajectories from the Atlantic Ocean due to the westerly flow that is frequent at the latitude of the measurement site. Their corresponding distances were also the greatest and may be attributed to the lack of orographic features in this direction.

$\mathrm{CO}_{2}$ and $\mathrm{CH}_{4}$ concentrations recorded over 6 years were described by a linear function that provided an average trend of around 2.34 and $0.0085 \mathrm{ppm} \mathrm{year}^{-1}$, in agreement
Table 5. Vegetation types following NDVI values.

\begin{tabular}{lc}
\hline Vegetation & NDVI \\
\hline Bare soil and dead vegetation & $0-0.2$ \\
Shrub or grassland & $0.2-0.4$ \\
Abundant vigorous vegetation & $0.4-0.6$ \\
Very dense and vigorous vegetation & $>0.6$ \\
\hline
\end{tabular}

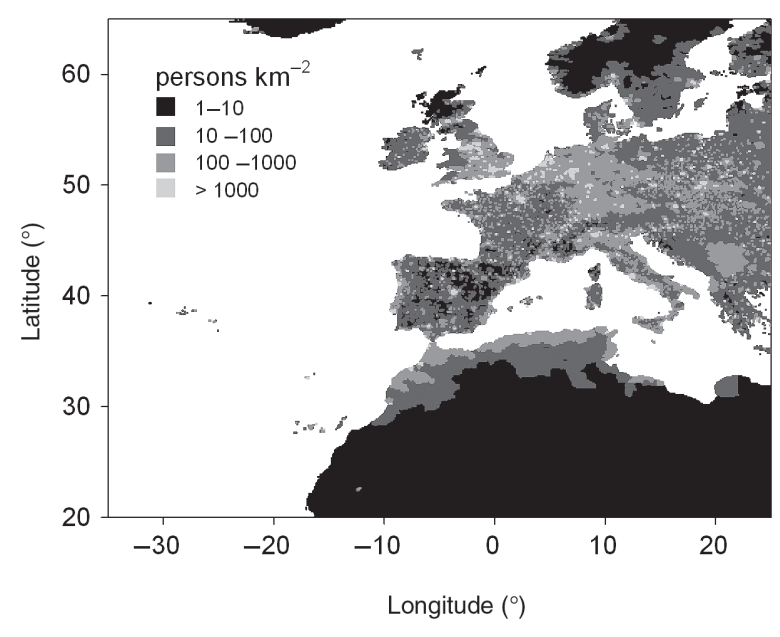

Figure 6. Population density in the region studied.

with values recorded at other sites. The yearly evolution of detrended concentrations was very smooth because monthly medians were in the interquartile ranges of all the observations, which were around 10.1 and $0.033 \mathrm{ppm}$ for $\mathrm{CO}_{2}$ and $\mathrm{CH}_{4}$, respectively. Only monthly medians in summer were lower than the first quartile.

Concentrations of both gases were considered in each corresponding trajectory group. The highest $\mathrm{CO}_{2}$ concentrations were linked to groups from northern Africa affected by local influence of nearby cities. However, the smallest values for both gases were associated with groups with the greatest frequencies whose trajectories came from the Atlantic Ocean. Contrasting trends were observed in summer because this was the highest for $\mathrm{CO}_{2}$, but the lowest for $\mathrm{CH}_{4}$.

Although the relationship between air trajectories and concentrations is not easy, the procedure proposed presented satisfactory results and extending it to other places and substances might prove desirable in order to gain deeper insights into its response.

\section{Acknowledgements}

The authors wish to acknowledge the financial support of the Ministry of Economy and Competitiveness and ERDF funds (project nos CGL2009-11979 and CGL2014-53948-P). The authors declare that there is no conflict of interests regarding publication of this article.

\section{References}

Artuso F, Chamard P, Piacentino S, Sferlazzo DM, De Silvestri L, di Sarra A, Meloni D, Monteleone F. 2009. Influence of transport 
and trends in atmospheric $\mathrm{CO}_{2}$ at Lampedusa. Atmos. Environ. 43 : 3044-3051. https://doi.org/10.1016/j.atmosenv.2009.03.027.

Cape JN, Methven J, Hudson LE. 2000. The use of trajectory cluster analysis to interpret trace gas measurements at Mace Head, Ireland. Atmos. Environ. 34: 3651-3663.

Dimitriou K, Kassomenos P. 2013. The fine and coarse particulate matter at four major Mediterranean cities: local and regional sources. Theor. Appl. Climatol. 114: 375-391. https://doi.org/10.1007/s00704-0130851-y.

Donnelly A, Misstear B, Broderick B. 2011. Application of nonparametric regression methods to study the relationship between $\mathrm{NO}_{2}$ concentrations and local wind direction and speed at background sites. Sci. Total Environ. 409: 1134-1144. https://doi.org/10.1016/j .scitotenv.2010.12.001

Donnelly AA, Broderick BM, Misstear BD. 2015. The effect of long-range air mass transport pathways on $\mathrm{PM}_{10}$ and $\mathrm{NO}_{2}$ concentrations at urban and rural background sites in Ireland: quantification using clustering techniques. J. Environ. Sci. Health A 50: 647-658. https://doi.org/10.1080/10934529.2015.1011955.

Dorling SR, Davies TD, Pierce CE. 1992. Cluster analysis: a technique for estimating the synoptic meteorological controls on air and precipitation chemistry - method and applications. Atmos. Environ. A 26 : $2575-2581$.

Fang SX, Tans PP, Dong F, Zhou H, Luan T. 2016. Characteristics of atmospheric $\mathrm{CO}_{2}$ and $\mathrm{CH}_{4}$ at the Shangdianzi regional background station in China. Atmos. Environ. 131: 1-8. https://doi.org/10.1016/j .atmosenv.2016.01.044.

Fisher NI. 1993. Statistical Analysis of Circular Data. Cambridge University Press: Cambridge, UK.

García MA, Sánchez ML, Pérez IA. 2012. Differences between carbon dioxide levels over suburban and rural sites in northern Spain. Environ. Sci. Pollut. Res. 19: 432-439. https://doi.org/10.1007/s11356-0110575-4.

García MA, Sánchez ML, Pérez IA, Ozores MI, Pardo N. 2016. Influence of atmospheric stability and transport on $\mathrm{CH}_{4}$ concentrations in northern Spain. Sci. Total Environ. 550: 157-166. https://doi.org/10 1016/j.scitotenv.2016.01.099.

Henry RC. 2008. Locating and quantifying the impact of local sources of air pollution. Atmos. Environ. 42: 358-363. https://doi.org/10.1016/j atmosenv.2007.09.039.

Henry RC, Chang YS, Spiegelman CH. 2002. Locating nearby sources of air pollution by nonparametric regression of atmospheric concentrations on wind direction. Atmos. Environ. 36: 2237-2244. https:// doi.org/10.1016/S1352-2310(02)00164-4.

Henry RC, Vette A, Norris G, Vedantham R, Kimbrough S, Shores RC. 2011. Separating the air quality impact of a major highway and nearby sources by nonparametric trajectory analysis. Environ. Sci. Technol. 45: 10471-10476. https://doi.org/10.1021/es202070k.

Hernández-Ceballos MA, Brattich E, Cinelli G. 2016. Heat-wave events in Spain: air mass analysis and impacts on ${ }^{7} \mathrm{Be}$ concentrations. $A d v$ Meteorol. 2016: 8026018. https://doi.org/10.1155/2016/8026018.

Hernández-Paniagua IY, Lowry D, Clemitshaw KC, Fisher RE, France JL, Lanoisellé M, Ramonet M, Nisbet EG. 2015. Diurnal, seasonal, and annual trends in atmospheric $\mathrm{CO}_{2}$ at southwest London during 2000-2012: wind sector analysis and comparison with Mace Head, Ireland. Atmos. Environ. 105: 138-147. https://doi.org/ 10.1016/j.atmosenv.2015.01.021.

Inoue HY, Matsueda H, Igarashi Y, Sawa Y, Wada A, Nemoto K, Sartorius H, Schlosser C. 2006. Seasonal and long-term variations in atmospheric $\mathrm{CO}_{2}$ and ${ }^{85} \mathrm{Kr}$ in Tsukuba, central Japan. J. Meteorol. Soc. Jpn. 84: 959-968. https://doi.org/10.2151/jmsj.84.959.

Institut Cartogràtic i Geològic de Catalunya (ICGC). 2017. http://www .icgc.cat/en/ (accessed 17 May 2017)

Kumar S, Devara PCS, Manoj MG, Safai PD. 2011. Winter aerosol and trace gas characteristics over a high-altitude station in the Western Ghats, India. Atmosfera 24: 311-328.

Li M, Huang X, Zhu L, Li J, Song Y, Cai X, Xie S. 2012. Analysis of the transport pathways and potential sources of $\mathrm{PM}_{10}$ in Shanghai based on three methods. Sci. Total Environ. 414: 525-534. https://doi.org/ 10.1016/j.scitotenv.2011.10.054

Liu M, Wu J, Zhu X, He H, Jia W, Xiang W. 2015. Evolution and variation of atmospheric carbon dioxide concentration over terrestrial ecosystems as derived from eddy covariance measurements. Atmos. Environ. 114: 75-82. https://doi.org/10.1016/j.atmosenv.2015 .05 .026 .

Markou MT, Kassomenos P. 2010. Cluster analysis of five years of back trajectories arriving in Athens, Greece. Atmos. Res. 98: 438-457. https://doi.org/10.1016/j. atmosres.2010.08.006.

Morgan WT, Allan JD, Bower KN, Capes G, Crosier J, Williams PI, Coe H. 2009. Vertical distribution of sub-micron aerosol chemical composition from north-western Europe and the north-east Atlantic. Atmos. Chem. Phys. 9: 5389-5401.

NEO-NASA Earth Observations. 2017. https://neo.sci.gsfc.nasa.gov/ (accessed 17 May 2017).

Notario A, Adame JA, Bravo I, Cuevas CA, Aranda A, Díaz-de-Mera Y, Rodríguez A. 2014. Air pollution in the plateau of the Iberian Peninsula. Atmos. Res. 145-146: 92-104. https://doi.org/10.1016/j .atmosres.2014.03.021.

Notaro M, Alkolibi F, Fadda E, Bakhrjy F. 2013. Trajectory analysis of Saudi Arabian dust storms. J. Geophys. Res. Atmos. 118: 6028-6043. https://doi.org/10.1002/jgrd.50346.

Pérez IA, Sánchez ML, García MA, de Torre B. 2009. $\mathrm{CO}_{2}$ transport by urban plumes in the upper Spanish Plateau. Sci. Total Environ. 407: 4934-4938. https://doi.org/10.1016/j.scitotenv.2009.05.037.

Pérez IA, Artuso F, Mahmud M, Kulshrestha U, Sánchez ML, García MA. 2015a. Applications of air mass trajectories. Adv. Meteorol. 2015: 284213. https://doi.org/10.1155/2015/284213.

Pérez IA, Sánchez ML, García MA, Pardo N. 2015b. Analysis of air mass trajectories in the northern plateau of the Iberian Peninsula. J. Atmos. Sol.-Terr. Phys. 134: 9-21. https://doi.org/10.1016/j.jastp .2015.09.003.

Pérez IA, Sánchez ML, García MA, Pardo N. 2016. Features of the annual evolution of $\mathrm{CO}_{2}$ and $\mathrm{CH}_{4}$ in the atmosphere of a Mediterranean climate site studied using a nonparametric and a harmonic function. Atmos. Pollut. Res. 7: 1013-1021. https://doi.org/10.1016/ j.apr.2016.06.006.

Saha S, Moorthi S, Wu X, Wang J, Nadiga S, Tripp P, Behringer D, Hou YT, Chuang HY, Iredell M, Ek M, Meng J, Yang R, Mendez MP, Van Den Dool H, Zhang Q, Wang W, Chen M, Becker E. 2014. The NCEP climate forecast system version 2. J. Clim. 27: 2185-2208. https://doi .org/10.1175/JCLI-D-12-00823.1.

Sánchez ML, Pérez IA, García MA. 2010. Study of $\mathrm{CO}_{2}$ variability at different temporal scales recorded in a rural Spanish site. Agric. For. Meteorol. 150: 1168-1173. https://doi.org/10.1016/j.agrformet.2010 .04 .018

Sánchez ML, García MA, Pérez IA, Pardo N. 2014. $\mathrm{CH}_{4}$ continuous measurements in the upper Spanish Plateau. Environ. Monit. Assess. 186: 2823-2834. https://doi.org/10.1007/s10661-013-3583-7.

Silverman BW. 1986. Density Estimation for Statistics and Data Analysis. Chapman and Hall: London.

Snyder JP. 1987. Map projections - a working manual. U.S. Geological Survey Professional Paper 1395, U.S. Government Printing Office, Washington, DC.

Srivastava S, Naja M, Thouret V. 2015. Influences of regional pollution and long range transport over Hyderabad using ozone data from MOZAIC. Atmos. Environ. 117: 135-146. https://doi.org/10.1016/j .atmosenv.2015.06.037.

Timokhina AV, Prokushkin AS, Onuchin AA, Panov AV, Kofman GB, Verkhovets SV, Heimann M. 2015. Long-term trend in $\mathrm{CO}_{2}$ concentration in the surface atmosphere over central Siberia. Russ. Meteorol. Hydrol. 40: 186-190. https://doi.org/10.3103/S106837391503005X.

Vermeulen AT, Hensen A, Popa ME, Van Den Bulk WCM, Jongejan PAC. 2011. Greenhouse gas observations from Cabauw Tall Tower (1992-2010). Atmos. Meas. Tech. 4: 617-644. https://doi.org/10 .5194/amt-4-617-2011

Wilks DS. 2011. Statistical Methods in the Atmospheric Sciences, 3rd edn. Academic Press: Oxford, UK.

Xu L, Chen J, Niu Z, Yin L, Chen Y. 2013. Characterization of mercury in atmospheric particulate matter in the southeast coastal cities of China. Atmos. Pollut. Res. 4: 454-461. https://doi.org/10.5094/APR .2013.052.

Zeng J, Matsunaga T, Mukai H. 2010. METEX - a flexible tool for air trajectory calculation. Environ. Modell. Software 25: 607-608. https:// doi.org/10.1016/j.envsoft.2008.10.015. 